\title{
PROGRAM BELAJAR ISLAM INTENSIF BAGI MUSLIMAH DI DESA KENARI, KABUPATEN POHUWATO, GORONTALO
}

\section{INTENSIVE ISLAMIC LEARNING PROGRAM FOR MUSLIMAH IN KENARI VILLAGE, POHUWATO REGENCY, GORONTALO}

\author{
Asnawati Patuti \\ Sekolah Tinggi Ilmu Islam dan Bahasa Arab (STIBA) Makassar \\ asnawati@stiba.ac.id \\ Riska \\ Sekolah Tinggi Islam dan Bahasa Arab (STIBA) Makassar \\ riska@stiba.ac.id \\ Eka Syahriani \\ Sekolah Tinggi Islam dan Bahasa Arab (STIBA) Makassar \\ ekasyahriani@stiba.ac.id
}

\begin{tabular}{|c|c|}
\hline Keywords : & ABSTRACT \\
\hline $\begin{array}{l}\text { KKN Gorontalo, Intensive } \\
\text { Islamic Learning, Kenari } \\
\text { Village }\end{array}$ & $\begin{array}{l}\text { Kenari Village is a village located in Lemito Subdistrict, Pohuwato } \\
\text { Regency, Gorontalo Province. The people of Kenari Village have a } \\
\text { religious character so that there are good enough da'wah } \\
\text { opportunities for students of KKN STIBA Makassar in Gorontalo to } \\
\text { develop the competence of da'wah in the field. The method of } \\
\text { implementation of KKN is started by conducting field surveys using } \\
\text { self-made instruments and then conducted SOAR analysis. After } \\
\text { conducting observations and consultations with the Muslimah } \\
\text { Wahdah Pahuwuto, then determined the kkn team work program as } \\
\text { follows: Friday Study, Tahfiz Qur'an Daily, Adult Qur'an Education } \\
\text { (Dirosa), Memorizing Hadith Kitabul Jami', Teaching Arabic, TPA / } \\
\text { TPQ, Tahsin (improving reading). As a result, the KKN program can } \\
\text { be carried out well and smoothlydespite some changes and additions } \\
\text { and time that are not as planned. As for the success achieved, it } \\
\text { appears to improve the quality of reading the Qur'an muslimah and } \\
\text { students in the location KKN. }\end{array}$ \\
\hline \multirow{2}{*}{$\begin{array}{l}\text { Kata kunci : } \\
\text { Desa Kenari, Belaiar Islami } \\
\text { Intensif, KKN Gorontalo }\end{array}$} & ABSTRAK \\
\hline & $\begin{array}{l}\text { Desa Kenari merupakan desa yang berada di Kecamatan Lemito, } \\
\text { Kabupaten Pohuwato, Provinsi Gorontalo. Masyarakat Desa Kenari } \\
\text { memiliki karakter yang religius sehingga terbuka peluang dakwah } \\
\text { yang cukup baik bagi mahasiswa KKN STIBA Makassar di } \\
\text { Gorontalo untuk mengembangkan kompetensi dakwah di lapangan. } \\
\text { Metode pelaksanaan KKN ini diawali dengan melakukan survei } \\
\text { lapangan dengan menggunakan instrumen buatan mandiri lalu } \\
\text { kemudian dilakukan analisis SOAR. Setelah melakukan observasi } \\
\text { dan konsultasi dengan pihak Muslimah Wahdah Pahuwuto, maka } \\
\text { kemudian ditentukanlah program kerja tim KKN sebagai beikut: } \\
\text { Kajian Jumat, Tahfiz Qur'an Harian, Pendidikan Al-Qur'an Orang } \\
\text { Dewasa (Dirosa), Menghafal Hadis Kitabul Jami', Pengajaran } \\
\text { Bahasa Arab, TPA/TPQ, Tahsin (perbaikan bacaan). Hasilnya, } \\
\text { program KKN dapat terlaksana dengan baik dan lancar meski ada }\end{array}$ \\
\hline
\end{tabular}


Website: https://journal.stiba.ac.id ISSN: 2723-6013 (Online)

beberapa perubahan dan tambahan serta waktu yang kurang sesuai dengan yang direncanakan. Adapun keberhasilan dicapai, itu tampak pada peningkatan kualitas membaca Al-Qur'an muslimah dan anak santri di lokasi KKN.

Diterima: 20 April 2021; Direvisi: 16 Mei 2021; Disetujui: 25 Mei 2021; Tersedia online: 18 Juni 2021

How to cite: Asnawati Patuti, Riska, Eka Syahriani, "Program Belajar Islam Intensif bagi Masyarakat Muslim Desa Kenari, Kabupaten Pohuwato, Gorontalo", WAHATUL MUJTAMA': Jurnal $\begin{array}{llllllll}\text { Pengabdian Masyarakat Vol.2, No.1 (Juni 18, 2021): 70-82. doi: } & & \end{array}$ https://doi.org/10.36701/wahatul.v2i1.346

\section{PENDAHULUAN}

Mata pencaharian masyarakat Desa Kenari didominasi oleh aktivitas pertanian. Hal tersebut dapat dilihat bahwa sebagian besar wilayah desa diperuntukkan untuk lahan pertanian. Di antara hasil pertanian yang ada di Desa Kenari yakni yang paling besar menyumbang pendapatan daerah adalah hasil pertanian jagung dan kelapa. Hasil pertanian lain yang dijadikan sebagai komoditi perdagangan adalah pisang, jagung, sereh, lengkuas, serta berbagai jenis hasil tanaman sayur-sayuran. Selain hasil bumi, mata pencaharian masyarakat Desa Kenari mencakup hasil peternakan berupa sapi, kambing, dan ayam. Seluruh penduduknya beragama Islam. Beberapa etnis menjadi penduduk desa ini, di antaranya adalah etnis mayoritas, etnis Jawa 12 orang, Bali 1 orang, Bugis 6 orang, Ternate 1 orang, Atinggola 1 orang, Otogim 1 orang, Babongko 1 orang, GeserGoro 1 orang, Tomini 2 orang. Karakteristik masyarakat Kenari sama seperti karakter etnis Gorontalo yang lain yaitu religius ${ }^{1}$.

Berdasarkan profil singkat Desa Kenari di atas, maka ditetapkan tujuan dari pelaksanaan pengabdian kepada masyarakat $(\mathrm{PkM})$ yang hendak dilakukan oleh pihak Sekolah Tinggi Ilmu Islam dan Bahasa Arab (STIBA) Makassar bekerja sama dengan Muslimah Wahdah Pahuwuto dalam bentuk KKN IV mahasiswa STIBA Makassar. Paparan tujuan disajikan sebagai berikut:

1. Menumbuhkan kesadaran sosial mahasiswa dalam berdakwah berbasis ilmu pengetahuan Islam yang telah diperoleh selama di STIBA Makassar.

2. Mengembangkan kompetensi dakwah lapangan mahasiswa STIBA Makassar.

3. Mengamalkan tri dharma perguruan tinggi bagi Dosen Pembimbing Lapangan (DPL) pada pilar pengabdian kepada masyarakat.

4. Mengembangkan eksistensi STIBA Makassar sebagai perguruan tinggi berbasis pengkaderan ulama dan organisatoris yang bermanfaat kepada masyarakat.

\footnotetext{
${ }^{1}$ Profil Desa Kenari
} 
Website: https://journal.stiba.ac.id ISSN: 2723-6013 (Online)

Metode pelaksanaan KKN ini yaitu diawali dengan melakukan survei lapangan dengan menggunakan instrumen buatan mandiri lalu kemudian dilakukan analisis SOAR. Tujuannya adalah untuk mengidentifikasi masalah yang terjadi di masyarakat, memetakan masalah, kebutuhan gerakan dakwah, dan menyusun strategi penyusunan program KKN yang meliputi bidang pendidikan, sosial, dan kesehatan. Berdasarkan survei lapangan masyarakat Kab. Pahuwato dengan analisis SOAR maka didapatkan sebagai berikut:

1. Strength, masyarakat Gorontalo berkarakter religius, etos kerja tinggi, dan soliditas yang baik. Mahasiswa STIBA Makassar telah dibekali pemahaman agama yang baik, memiliki keterampilan dakwah dan terlatih dalam mengajarkan metode tilawati dan metode dirosa untuk pengajaran Al-Qur'an.

2. Opportunities, dukungan dan kerjasama dengan pihak organisasi dakwah setempat yaitu Muslimah Wahdah Pahuwuto.

3. Aspiration, Desa Pahuwuto menjadi desa binaan, supaya karakter masyarakat yang religius menjadi semakin kental dengan keberlanjutan program-program Al-Qur'an.

4. Result, terwujudnya Desa Pahuwuto sebagai desa yang bernuansa Islami, mengenal, membaca, menghafal dan mengamalkan Al-Qur'an.

Dari analisis sederhana di atas, maka bentuk PkM berwujud KKN dipetakan menjadi program-program dakwah berupa Kajian Jumat, Tahfiz Qur'an Harian, Pendidikan Al-Qur'an Orang Dewasa (Dirosa), Menghafal Hadis Kitabul Jami', Pengajaran Bahasa Arab, TPA/TPQ, dan Tahsin (Perbaikan Bacaan),

Sehubungan dengan itu pula, telah terdapat beberapa PkM terdahulu relevan dengan PkM ini, di antaranya:

1. PkM yang dilaksanakan oleh Ramsan, mendeskripsikan model pembelajaran Tamyiz. Pada model pembelajaran Tamyiz tampak berusaha memberikan kontribusi dalam pembelajaran bahasa Arab yang lebih cepat dan komprehensif. Menurut pendukungnya, Tamyiz efektif dalam menciptakan kemampuan berbahasa Arab secara kilat ${ }^{2}$.

2. Uswah dan kawan-kawan melaksanakan PkM yang bertujuan untuk memberikan pembinaan kepada mitra tentang manajemen pembelajaran dan sosialisasi tahsin tilawah Al-Qur'an kepada masyarakat yang ditujukan kepada ibu-ibu di lingkungan pengabdian yang mana bermanfaat dalam pelaksanaan program. Penyusunan jadwal kegiatan merupakan kegiatan yang mengawali

${ }^{2}$ Sebagai Bahasa and Al- Q U R An, "Tamyiz; Model Alternatif Pembelajaran Bahasa Arab Sebagai Bahasa Al-Qurâ€ $€^{\mathrm{TM}}$ an," Lisanul' Arab: Journal of Arabic Learning and Teaching 6, no. 1 (2017): 18-28, https://doi.org/10.15294/la.v6i1.14389. 
program, dilanjutkan dengan pembinaan dan motivasi, pelatihan manajemen pembelajaran, evaluasi program, sosialisasi dan evaluasi akhir ${ }^{3}$.

3. Kegiatan PkM (Pengabdian Kepada Masyarakat) juga dilaksanakan oleh Agus Milu Susetyo di TPQ Baitul Hakim Desa Bangorejo, Kab. Banyuwangi. Kegiatan utamanya adalah pelatihan penambahan materi ajaran agama Islam melalui gubahan lirik lagu anak-anak. Kegiatan PkM ini dilaksanakan berdasarkan pada pemahaman penulis atas konsep pembelajaran apapun haruslah fun/menyenangkan. Hal itu bertujuan agar peserta didik atau santri merasakan dan tidak jenuh selama pembelajaran. Selain itu, kecerdasan musikal berfungsi antara lain sebagai berikut: (a) Meningkatkan kreativitas dan imajinasi; (b) Meningkatkan intelektualitas; (c) Mempengaruhi kecerdasan lainnya; (d) Terapi psikologis ${ }^{4}$.

4. Dengan tema Upaya Meningkatkan Motivasi Anak Mempelajari Al- Qur'an Melalui Vidio Animasi Pada Masa Pandemi Covid- 19, Nida K. H., dan Maemunah Sa'diyah mengadakan PkM bertujuan untuk memberikan motivasi khususnya pada anak dalam mempelajari Al-Qur'an melalui video animasi, agar anak tetap semangat mempelajari Al-Qur'an pada masa pandemi Covid19. Hasil penelitian menunjukan bahwa melalui video animasi pembelajaran, sehingga ada motivasi yang diberikan untuk anak dalam memahami pembelajaran Al-Qur'an yang mampu meningkatkan semangat anak dalam mempelajari Al-Qur'an. Dengan video pembelajaran hadir sebagai jawaban yang mampu meningkatkan motivasi belajar yang efektif agar di dalam hati setiap anak selalu menumbuhkan kecintaan terhadap Al-Qur'an ${ }^{5}$.

5. Muhamad Ansori juga mengadakan PkM yang bertujuan untuk mengembangkan aset komunitas lembaga SD Plus Al-Qodiri Jember pada aspek kualitas SDM guru dalam menerapkan variasi metode tahfiz berupa APEL dan Muraja'ah dalam program tahfiz pada siswa di Masa Covid-19. Proses pemberdayaan ini menggunakan pendekatan ABCD. Pelaksanaan pemberdayaan berjalan dengan optimal karena pemberdayaan ini menghasilkan pengembangan kualitas aset SDM guru-guru SD Plus Al-Qodiri dalam memanfaatkan penggunaan metode yang variatif dan tepat sesuai kondisi dan situasi yang sekarang dihadapi. Temuan berikutnya menunjukkan

${ }^{3}$ Hasanah, Uswah, et al. "PKM Pembinaan Taman Baca Al Quran Dalam Pembelajaran Tahsin Tilawah di Kelurahan Sari Rejo, Medan Polonia." IHSAN: Jurnal Pengabdian Masyarakat 2.1 (2020): 101-111.

${ }^{4}$ Pelatihan Membaca, Al- Q U R An, and Yang Baik, “Agus Milu Susetyo FKIP Universitas Muhammadiyah Jember PENDAHULUAN Pendidikan Karakter Saat Ini Merupakan Sebuha Hal Yang Penting. Pemerintah Sekarang Sedang Gencar-Gencarnya Merubah Dan Merombak Kurikulum Pendidikan Di Indonesia . Kurikulum Yang Berbasi,” no. c (n.d.): 34-42.

${ }^{5} \mathrm{Q}$ U R An et al., "UPAYA MENINGKATKAN MOTIVASI ANAK MEMPELAJARI AL" 4, no. 1 (2020). 
bahwa pendampingan yang telah dilakukan di komunitas ini ternyata berdampak pada penambahan sarana pendidikan, jumlah tenaga pengajar dan alokasi waktu di lembaga tersebut. Metode Tahfiz Juz 'Amma di komunitas tersebut semakin bertambah dan variatif sehingga metode-metode menghafal ini akan sangat membantu para siswa untuk mengembangkan dan meningkatkan daya ingat siswa dalam hafalan juz 'amma (surat-surat pendek) ${ }^{6}$.

PkM di atas menunjukkan bahwa program pengabdian KKN mahasiswa di bidang pengajaran Al-Qur'an, dan Bahasa Arab pernah diadakan sebelumnya, yang menjadi beberapa perbedaan pada program KKN STIBA Makassar angkatan IV di daerah Gorontalo adalah metode pendekatan yang menggunakan pendekatan analisis SOAR dan pelaksanaan program mengajar Al-Qur'an yang menggunakan metode DIROSA.

\section{PEMBAHASAN}

Pada pelaksanaan KKN kali ini merupakan KKN virtual ke-2 oleh STIBA Makassar selama pandemi, sehingga tidak ada penyambutan atau perhelatan secara simbolis dari aparat desa dalam menyambut mahasiswa. Untuk memudahkan pelaksanaan program kerja mahasiswa KKN bekerjasama dengan pihak Muslimah Wahdah Pahuwato, yang mana merupakan organisasi dakwah kemuslimahan di bawah naungan Wahdah Islamiyah. Setelah melakukan observasi dan konsultasi dengan pihak Muslimah Wahdah Pahuwuto, selanjutnya ditentukanlah program kerja tim KKN sebagai beikut: Kajian Jum'at, Tahfiz Qur'an harian, Pendidikan Al-Qur'an Orang Dewasa (Dirosa), Menghafal Hadis Kitabul Jami', Pengajaran Bahasa Arab, TPA/TPQ, dan Tahsin (Perbaikan Bacaan),

\section{Kajian Jumat}

Kajian Jumat merupakan suatu kegiatan yang berorientasi pada remaja kalangan SMA/Sederajat. Kamat adalah kegiatan rutin pekanan yang diadakan oleh UNIT PQ2 Muslimah Wahdah Pohuwato yang kemudian diamanahkan ke mahasiswa KKN untuk mengolah dan mensukseskan program tersebut selama waktu KKN. Kegiatan ini bertujuan untuk memberikan wawasan tentang Islam kepada para remaja. Selain itu, yang paling penting juga adalah pencerahan kalbu pada kajian Jumat (taklim muslimah) berarah tujuan dalam meningkatkan iman pada diri seseorang ${ }^{7}$. 58.

6 “Nizan Abu, 2008, Buku Pintar, Jakarta: Qultum Media, h. 7. 139” 1, no. 2 (2021): 139-

${ }^{7}$ Putri, Sri Ujiana, and Aswar Aswar. "Implementasi Pendidikan Masyarakat Berbasis Masjid untuk Muslimah di Desa Mattoanging Kabupaten Maros." WAHATUL MUJTAMA': Jurnal Pengabdian Masyarakat 1.2 (2020): 129-141. 


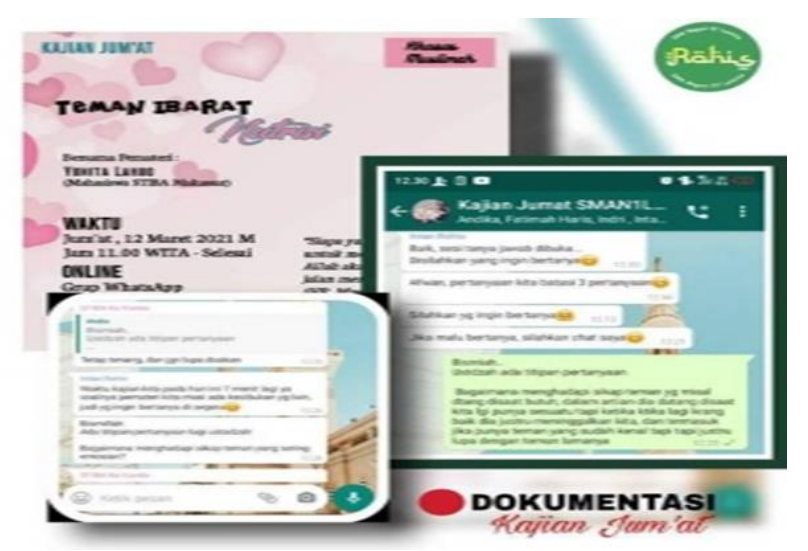

Gambar 1. Kajian Jumat Virtual

Target kegiatan ini adalah para siswi SMAN 01 Lemito dan siswi SMKN Wanggarasi. Kegiatan yang berlangsung pada hari Jumat, 05 Maret 2021 dan Jumat, 12 Maret 2021. Dimulai pada pukul 10.00 sampai 12.30, diawali penyampaian materi dan diakhiri dengan tanya jawab dari para peserta. Melalui platform Whatsapp kegiatan ini diadakan setiap pekannya. Tentunya, hal ini menjadi pengalaman menarik bagi mahasiswa KKN karena untuk pertama kalinya memberikan materi ke siswa Sekolah Menengah Atas melalui platform Whatsapp yang diketahui bersama tidak memfasilitasi interaksi lebih banyak dibanding platform lain seperti Zoom ataupun Google meet.

Kendala yang ditemukan selama kegiatan berlangsung adalah jaringan yang kadang tiba-tiba lemah dan adanya peserta tidak aktif mengikuti kajian karena kurang dikontrol oleh pelaksana. Hasil kegiatan ini adalah antusias peserta yang meningkat pada saat sebelum dan setelah program. Terlihat pada feedback peserta di sesi tanya jawab. Jumlah peserta yang bertanya pada saat kajian melebihi dari hari yang sebelumnya. Adapun keberlanjutan program ini diupayakan tetap berjalan, sebagaimana awalnya, akan dikembalikan kepada Unit P2Q Muslimah Wahdah Daerah Pohuwato.

\section{Tahfiz Qur'an Harian}

Tahfiz Qur'an Harian merupakan program kerja yang dilakukan oleh mahasiswi KKN angkatan IV STIBA Makassar daerah Gorontalo yang dilakukan setiap hari secara virtual. Sebagian juga mendapatkan halaqoh atau kelompok belajar dari binaan Muslimah Wahdah Gorontalo. Kegiatan ini bertujuan agar muslimah daerah Gorontalo bisa menghafalkan Al-Qur'an secara rutin. Selain itu, Daily Tahfidz (Tahfiz Harian) bermanfaat sebagai sarana penyetoran hafalan 
perbaikan bacaan, menambah jumlah setoran hafalan, dan memperbaiki bacaan atau hafalan yang keliru ${ }^{8}$.

Kegiatan ini dilaksanakan tiap hari melalui platform Whatsapp, dengan target kegiatan muslimah Gorontalo. Target program ini lebih luas mengingat semua program KKN selama masa pandemi melalui daring. Kegiatan ini berlangsung sacara online setiap hari. Metode pelaksanaan kegiatan ini adalah peserta mengirimkan hafalannya dalam bentuk voice note, bagi yang terkendala melalui telpon langsung penanggung jawabnya.

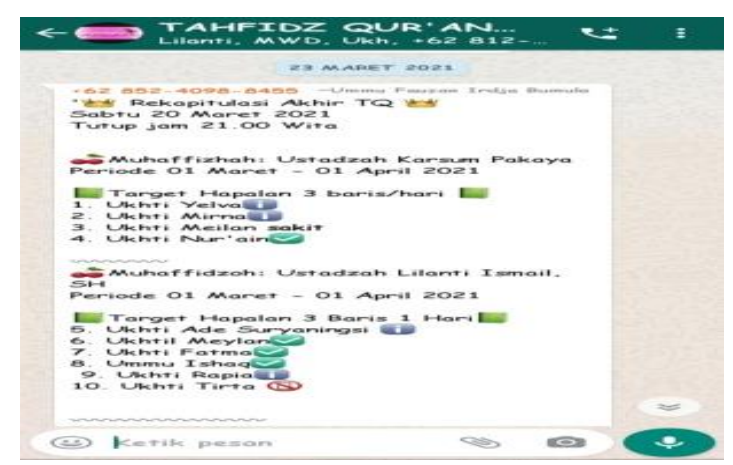

Gambar 2. Tahfiz Qur'an Virtual

Selanjutnya penanggung jawab akan mengoreksi bacaan maupun hafalannya peserta. Meskipun program ini hanya dilaksanakan secara online tetapi para peserta sangat antusias bahkan pengurus Muslimah Wahdah Pahuwuto juga ikut menjadi peserta. Hasil dari kegiatan terlihat pada perubahan sebelum dan setelah program kerja. Sebelum program kerja dilaksanakan, tampak peserta kurang wawasan tentang tempat keluarnya huruf dan sifat huruf dan kurangnya antusias dari para peserta. Selama dan setelah program kerja dilaksanakan, tampak bertambahnya wawasan tentang tempat keluarnya huruf dan sifat-sifatnya karena di akhir penyetoran ada perbaikan bacaan untuk peserta. Para peserta sangat antusias dalam menyetorkan hafalannya meskipun dalam kesibukan terutama para ibu-ibu. Adapun keberlanjutan program ini adalah akan dilanjutkan oleh pihak Muslimah Wahdah setempat.

\section{Pendidikan Al-Qur'an Orang Dewasa (DIROSA)}

Pendidikan Al-Qur'an Orang Dewasa merupakan program kerja mahasiswi KKN angkatan IV STIBA Makassar daerah Gorontalo yang berorientasi pada orang dewasa. DIROSA bertujuan untuk memperbaiki bacaan Al-Qur'an dan agar masyarakat dekat dengan Al-Qur'an. Adapun Hendra dan Nurhidayah melengkapi

8 Tempo, Rachmat Bin Badani, and Khaerul Aqbar. "Ikhtiar Mahasiswa KKN STIBA Makassar dalam Pembentukan Akhlak Qur'ani Masyarakat Desa Balassuka Kabupaten Gowa." WAHATUL MUJTAMA': Jurnal Pengabdian Masyarakat 1.1 (2020): 90-115. 
tujuan dari pengajaran DIROSA yaitu: (1) Meningkatkan motivasi dalam mempelajari dan mengajarkan Al-Qur'an bagi remaja dan orang dewasa; (2) Memberikan pembelajaran baca Al-Qur'an kepada remaja dan orang dewasa agar dapat membaca sesuai ilmu tajwid; dan (3) Memberikan tambahan ilmu dasardasar keislaman kepada remaja dan orang dewasa ${ }^{9}$.

Diadakan setiap hari Senin sampai hari Sabtu dengan 2 metode yaitu daring dan 1 kali melalui luring. Pengajaran secara offline berlangsung setiap Senin-Sabtu dengan menggunakan metode nada khusus yang bertujuan agar peserta cepat dalam memahami materi. Pengajaran secara online yaitu berlangsung dengan metode di mana pengajar mengirim materi lewat voice note di platform Whatsapp yang kemudian para peserta mendengar dan merekam bacaannya, dan setelah itu pengajar mulai memperbaiki bacaan peserta. Peserta terlihat sangat antusias dan merasa lebih mudah dalam mengikuti proses belajar Al-Qur'an yang mana peserta berasal dari kalangan ibu-ibu. Kendala yang dihadapi adalah waktu penyertoran bacaan yang sangat dinamis dikarenakan kesibukan para peserta di rumah dan tempat kerjanya masing-masing.

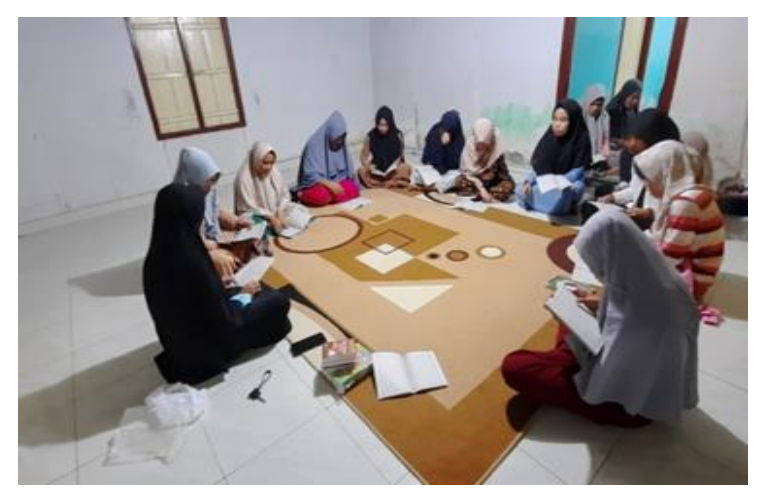

Gambar 3. Kegiatan Pengajaran Dirosa

Sebelum program dilaksanakan terlihat kurang antusiasnya para peserta kalangan remaja dan ibu-ibu dalam mempelajari Al-Qur'an bahkan ada beberapa ibu-ibu yang belum mengenal huruf hijaiah. Selama program berlangsung tampak semangat para peserta dalam mempelajari Al-Qur'an meskipun banyak urusanurusan pribadi. Akhirnya, seluruh peserta kemudian dapat mengenal huruf hijaiah. Untuk keberlangsungan program ini, maka akan dilanjutkan oleh pihak Muslimah Wahdah setempat.

9 Wijaya, Hendra. "Pembelajaran Metode Dirosa di Desa Majannang Kabupaten Gowa." WAHATUL MUJTAMA': Jurnal Pengabdian Masyarakat 1.1 (2020): 67-74. 


\section{Menghafal Hadis Kitabul Jami'}

Berikutnya yang menjadi program kerja mahasiswa KKN daerah Gorontalo adalah menghafal hadis Kitabul Jami'. Kegiatan ini bertujuan agar masyarakat mengenal hadis-hadis Rasulullah shalallahu 'alaihi wasallam, serta dapat menghafalkannya secara rutin. Senin-Sabtu pukul 08.00-22.00 WITA. Kegiatan ini berlangsung setiap hari Senin sampai Sabtu secara online. Metode kegiatannya dengan cara peserta menghafalkan hadis yang diberikan oleh pengajar, yang selanjutnya peserta mengirimkan hafalannya lewat voice note Whatsapp dan setiap akhir pekan di hari terakhir peserta mengulang (muroja'ah) hafalannya. Meskipun melalui online, peserta cukup antusias, hal ini dilihat pada komitmen peserta mengirimkan hafalannya ke penanggung jawab program. Perbedaan sebelum dan sesudah program kemudian dilihat pada peserta yang belum pernah menghafalkan hadis. Juga sebagian peserta kaku dalam membacakan hadis. Setelah program terlaksana, tampak bertambahnya wawasan peserta tentang hadis-hadis Rasulullah saw., juga mereka tampak lancar dalam membacakan hadis meskipun terlambat dalam penyetoran, peserta tetap antusias dalam menghafalkannya. Untuk keberlangsungan program ini maka akan dilanjutkan oleh pihak Muslimah Wahdah setempat.

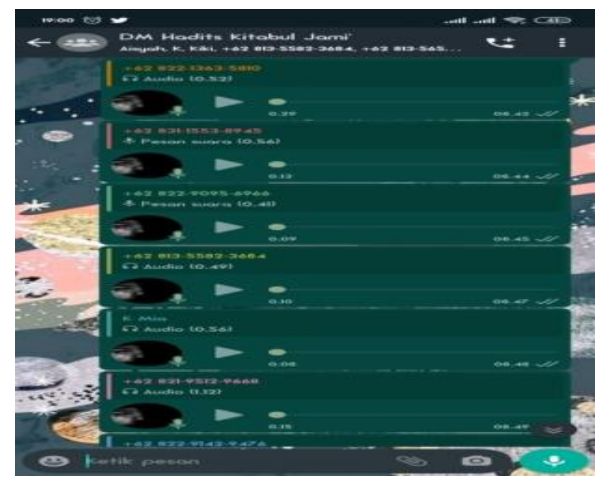

\section{Gambar 4. Kegiatan Menghafal Kitabul Jami’ Virtual}

\section{Pengajaran Bahasa Arab}

Salah satu program yang diminta oleh pihak muslimah di lokasi KKN adalah Pengajaran Bahasa Arab. Kegiatan ini bertujuan agar para muslimah daerah Gorontalo mengetahui dasar-dasar bahasa Arab. Selain itu, menurut Asnawati dan Rahmat menyatakan bahwa pengajaran bahasa Arab juga bertujuan agar seseorang dapat memahami Al-Qur'an dan hadis sebagai sumber hukum ajaran Islam melalui penambahan wawasan keilmuan tentang kosa kata bahasa Arab $^{10}$.

${ }^{10}$ Patuti, Asnawati. "Pelaksanaan Program Pendekatan Keagamaan melalui KKN STIBA Makassar di Desa Baruga Kabupaten Maros." WAHATUL MUJTAMA': Jurnal Pengabdian Masyarakat 1.2 (2020): 185-199. 


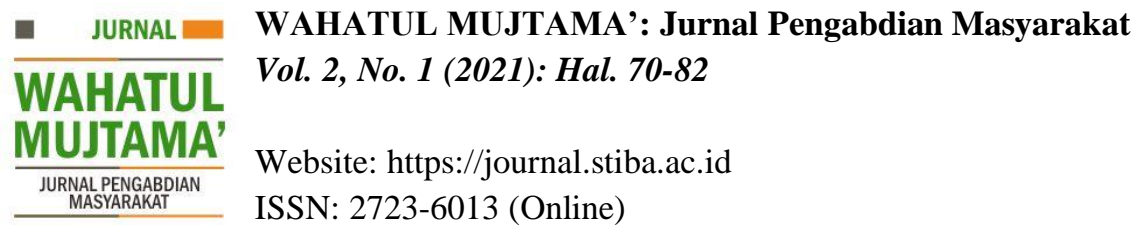

Kegiatan ini dilakukan secara virtual yaitu melalui link Youtube dan Zoom dan secara offline. Kegiatan ini berlangsung 3 kali dalam sepekan. Secara online dilaksanakan melalui via Zoom \& Whatsapp dan secara offline dilaksanakan di salah satu Rumah Qur'an yang ada di Kota Gorontalo. Berlangsung selama 1 jam atau lebih, dan didukung dengan latihan soal dan pertanyaan dari para peserta. Program ini berjalan dengan sangat baik karena peserta telah memahami dengan baik urgensi belajar bahasa Arab sehingga mereka sangat antusias dan didukung dengan adanya pertemua 1 kali dalam sepekan secara offline.

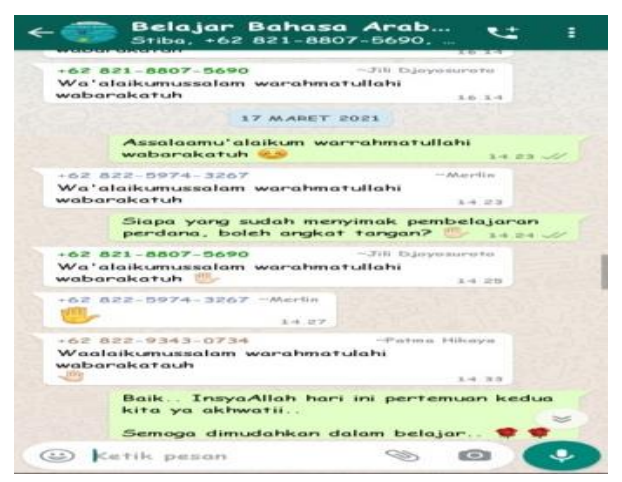

\section{Gambar 5. Pengajaran Bahasa Arab Virtual}

Perubahan yang terlihat adalah dari peserta yang kurang antusias dalam mempelajari bahasa Arab dan kurangnya pengetahuan dasar tentang ilmu bahasa Arab. Hal ini tentunya menjadi semangat peserta dalam mengikuti pembelajaran bahasa Arab dan bertambahnya wawasan dan kemampuan dalam bahasa Arab, baik dalam kosakata, bentuk percakapan bahasa Arab, dan angka-angka dalam bahasa Arab. Selanjutnya program ini akan dilanjutkan oleh pihak Muslimah Wahdah setempat.

\section{Pembinaan TPA/TPQ}

Pembinaan TPA/TPQ merupakan suatu kegiatan yang berorientasi pada anak usia 5-15 tahun. TPA/TPQ ini merupakan salah satu milik Yayasan Bina Muslim Gorontalo. Bertujuan untuk memberikan pengajaran membaca Al-Qur'an sejak usia dini dan membantu pertumbuhan kerohanian serta rasa cinta terhadap AlQur'an sebagai pedoman hidup. Kegiatan ini berlangsung pada hari Senin-Kamis pukul 13.00-16.00. Metode belajar, para peserta membaca Al-Qur'an kemudian pengajar mengoreksi bacaan tersebut. Setelah menyetorkan bacaan, peserta menghafalkan doa dalam kitab perisai muslim, menulis huruf hijaiah dan diselingi dengan games atau permainan agar peserta tidak bosan dan tetap bersemangat mengikuti kegiatan. Sehubungan dengannya Iskandan dan Amirullah mengatakan bahwa dalam proses pembelajaran di TPA santri terkadang bosan dengan sistem 
pengajaran yang biasa-biasa saja sehingga diperlukan semacam permainan (ice breaking) agar anak-anak santri kembali semangat dan fokus ${ }^{11}$. Adapun anak didik atau santri TK/TPQ pada proses pengajaran tampak sangat antusias, dan hal yang menarik adalah terjalinnya hubungan yang sangat baik dengan para ibu peserta TPA/TPQ.

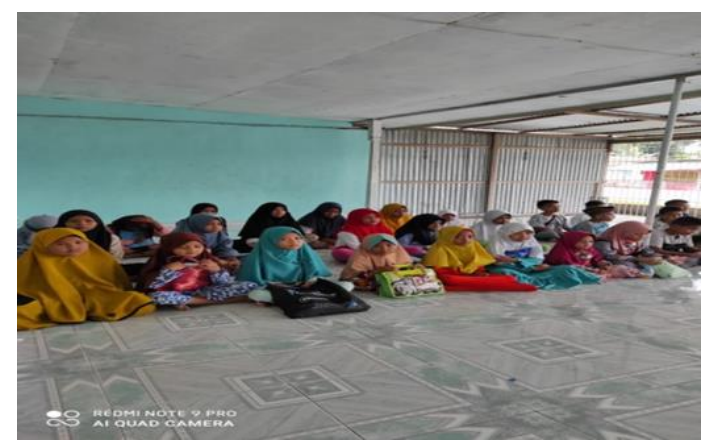

Gambar 6. Pembinaan TK/TPA

Awal perkenalan bersama ibu-ibu tidak ada keakraban antar ibu-ibu dan pengajar, maka tepatlah pepatah berbunyi, "Tak kenal maka tak sayang." Dengan demikian, hasil program ini adalah perubahan dari sebelum program yaitu kurangnya semangat dalam belajar Al-Qur'an. Tampak pula ada rasa takut terhadap pengajar karena belum ada pengenalan dan umumnya peserta kurang memahami ilmu tajwid. Selama dan setelah program berlangsung terlihat bertambahnya semangat anak-anak setelah melalui pengenalan antar pengajar dan anak-anak. Hilangnya rasa takut setelah adanya interaksi antara pengajar dan anak-anak, serta pengucapan huruf-huruf hijaiah yang sudah sesuai dengan tajwid. Berikutnya program ini akan dilanjutkan oleh pihak Yayasan Bina Muslim Gorontalo

\section{Tahsin (Perbaikan Bacaan)}

Tahsin atau perbaikan bacaan Al-Qur'an ini berlangsung setiap 1 kali sepekan. Dengan metode pembelajaran yaitu: dimulai dengan penyetoran hafalan dari para peserta, setelah itu pengajar memberikan materi dan tahsin (perbaikan bacaan). Adapun beberapa hal yang perlu dipelajari dalam halaqah tahsin adalah tadarus, perbaikan bacaan, penjelasan kaidah dan pengaplikasian hukum tajwid, pemberian motivasi dan keutamaan dalam memepelajari Al-Qur'an dan hal-hal

${ }^{11}$ Iskandar, Iskandar, and Muhammad Amirullah. "Pelaksanaan Dirasah Qur'aniyah sebagai Upaya Peningkatan Kualitas Baca Al-Qur'an di Desa Tukamasea Kabupaten Maros." WAHATUL MUJTAMA': Jurnal Pengabdian Masyarakat 1.1 (2020): 42-53. 
yang berkaitan dengannya ${ }^{12}$. Kendala dalam pelaksanaan program ini adalah banyaknya peserta yang berasal dari luar kecamatan, sehingga terkadang saat kegiatan berlangsung peserta kurang lengkap dari jumlah pendaftar awal di hari yang telah disepakati bersama. Untuk itu, solusi yang diberikan oleh penganggung jawab program adalah bagi peserta yang tidak bisa hadir di hari yang telah ditentukan, agar tetap datang di hari yang lain.

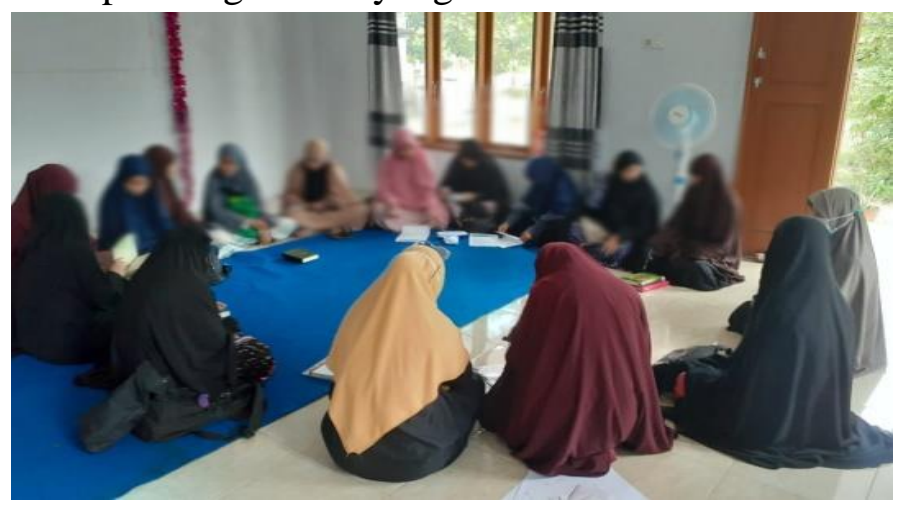

Gambar 7. Kegitan Tahsin (Perbaikan Bacaan)

Hasil program kerja ini adalah yang sebelum terlaksananya program diketahui bahwa peserta masih minim pengetahuan tentang tempat keluarnya huruf, dan setelah program terlaksana menjadi mengetahui dan mampu membedakan tempat keluarnya huruf. Selanjutnya program, tahsin ini dialihkan kepada MWD (Muslimah Wahdah) Gorontalo Utara agar programnya tetap berlanjut.

\section{KESIMPULAN}

Kegiatan KKN IV STIBA Makassar dengan sasaran masyarakat di beberapa Provinsi Gorontalo berjalan dengan lancar sesuai dengan apa yang direncanakan dalam program kerja $\mathrm{KKN}$, serta tampak perubahan positif yang terjadi di masyarakat seperti antusiasme dalam belajar Al-Qur'an dan hadis, serta pemahaman keislaman. Meski target waktu yang direncanakan dalam matriks program kerja tidak dapat sepenuhnya dijalankan. Namun tidak merubah dari esensi pelaksanaan program kerja tersebut.

\section{DAFTAR PUSTAKA}

Hidayat, Nida Khofyya, and Maemunah Sa'diyah. "Upaya Meningkatkan Motivasi Anak Mempelajari Al-Qur'an Melalui Vidio Animasi Pada Masa Pandemi Covid-19." PKM-P 4.1 (2020): 124-132.

Himam, Muhammad Wafaul, and Raswan Raswan. "Tamyiz; Model Alternatif

12 Putri, Sri Ujiana, and Aswar Aswar. "Implementasi Pendidikan Masyarakat Berbasis Masjid untuk Muslimah di Desa Mattoanging Kabupaten Maros." WAHATUL MUJTAMA': Jurnal Pengabdian Masyarakat 1.2 (2020): 129-141. 
Pembelajaran Bahasa Arab Sebagai Bahasa Al-Qur'an." Lisan Al-Arab: Journal of Arabic Language And Arabic Teaching 6.1 (2017): 18-28. https://doi.org/10.15294/la.v6i1.14389.

Iskandar, Iskandar, and Muhammad Amirullah. "Pelaksanaan Dirasah Qur'aniyah sebagai Upaya Peningkatan Kualitas Baca Al-Qur'an di Desa Tukamasea Kabupaten Maros." WAHATUL MUJTAMA': Jurnal Pengabdian Masyarakat 1.1 (2020): 42-53.

Membaca, Pelatihan, Al- Q U R An, and Yang Baik. "Agus Milu Susetyo FKIP Universitas Muhammadiyah Jember PENDAHULUAN Pendidikan Karakter Saat Ini Merupakan Sebuha Hal Yang Penting . Pemerintah Sekarang Sedang Gencar-Gencarnya Merubah Dan Merombak Kurikulum Pendidikan Di Indonesia . Kurikulum Yang Berbasi," no. c (n.d.): 34-42.

"Nizan Abu, 2008, Buku Pintar, Jakarta: Qultum Media, h. 7. 139" 1, no. 2 (2021): 139-58.

Patuti, Asnawati. "Pelaksanaan Program Pendekatan Keagamaan melalui KKN STIBA Makassar di Desa Baruga Kabupaten Maros." WAHATUL MUJTAMA': Jurnal Pengabdian Masyarakat 1.2 (2020): 185-199.

Putri, Sri Ujiana, and Aswar Aswar. "Implementasi Pendidikan Masyarakat Berbasis Masjid untuk Muslimah di Desa Mattoanging Kabupaten Maros." WAHATUL MUJTAMA': Jurnal Pengabdian Masyarakat 1.2 (2020): 129141.

Tempo, Rachmat Bin Badani, and Khaerul Aqbar. "Ikhtiar Mahasiswa KKN STIBA Makassar dalam Pembentukan Akhlak Qur'ani Masyarakat Desa Balassuka Kabupaten Gowa." WAHATUL MUJTAMA': Jurnal Pengabdian Masyarakat 1.1 (2020): 90-115.

Hasanah, Uswah, et al. "PKM Pembinaan Taman Baca Al Quran Dalam Pembelajaran Tahsin Tilawah di Kelurahan Sari Rejo, Medan Polonia." IHSAN: Jurnal Pengabdian Masyarakat 2.1 (2020): 101-111.

Wijaya, Hendra. "Pembelajaran Metode Dirosa di Desa Majannang Kabupaten Gowa." WAHATUL MUJTAMA': Jurnal Pengabdian Masyarakat 1.1 (2020): 67-74. 